\title{
The learning curve of retinal detachment surgery
}

\author{
Viola Radeck ${ }^{1} \cdot$ Horst Helbig $^{1}$ (D) $\cdot$ Teresa Barth $^{1} \cdot$ Maria-Andreea Gamulescu ${ }^{1} \cdot$ David Maerker $^{1} \cdot$ Philipp Prahs $^{1}$
}

Received: 25 November 2020 / Revised: 19 January 2021 / Accepted: 22 January 2021 / Published online: 5 February 2021

(C) The Author(s) 2021

\begin{abstract}
Purpose To investigate the learning curve of vitreoretinal (VR) surgeons beginning training in retinal detachment (RD) surgery. Methods The files of all consecutive patients undergoing VR surgery for uncomplicated RD between Jan 2005 und Mar 2020 were retrospectively reviewed. Successful outcome was defined as no retinal redetachment within 3 months after surgery.

Results Ten surgeons started their VR career during this period. Together, these 10 surgeons performed 3786 RD operations (mean 379; median 251; range 71-1053). Primary success rate after one operation was 90\% (3420 of 3786). When starting to operate retinal detachments, VR surgeons had a primary success rate of about $80 \%$. Redetachment rates steadily decreased and stabilized at just under $10 \%$ after about 200 operations. Beginners needed more than twice the time for the procedure compared to experienced surgeons. The individual learning curves varied widely. In our series, female surgeons seem to have a faster learning curve.

Conclusion RD surgery performed by VR surgeons in training had acceptable results. With increasing experience, success rates continuously improve reaching stable levels after approximately 200 operations. The training of VR surgeons requires considerable resources.
\end{abstract}

\section{Key messages}

- Learning surgery requires training and experience.

- Ophthalmologists beginning surgery for uncomplicated retinal detachment have acceptable anatomic success rates of about $80 \%$, after approximately 200 operations the rate of redetachment stabilizes just below $10 \%$.

- Female surgeons appeared to have a faster learning curve.

- Teaching surgery needs considerable resources.

Keywords Buckle surgery $\cdot$ Learning curve $\cdot$ Retinal detachment surgery $\cdot$ Training $\cdot$ Vitrectomy

\section{Introduction}

"Doctor, how many times have you performed retinal detachment $(\mathrm{RD})$ surgery?" is a frequently asked question during the conversation before surgery, especially if the surgeon looks young.

Horst Helbig

horst.helbig@ukr.de

1 Department of Ophthalmology, University Hospital of Regensburg, Franz-Josef-Strauss-Allee 11, DE-93042 Regensburg, Germany
Subspecialization and surgical training in ophthalmology are organized differently in different countries. Most healthcare systems provide no financial compensation for teaching surgery. Some have formal fellowships for subspecialties; others have training in general ophthalmic surgery following an ophthalmology residency. In Germany, the specialization in ophthalmology does not require intraocular surgery (except intravitreal injections), and thereafter, no further formal requirements for surgical training exist.

The law of patient rights in Germany ("Patientenrechtegesetz" BGB $\S 630 \mathrm{~h} \mathrm{Abs} \mathrm{4)} \mathrm{determines} \mathrm{that} \mathrm{if} \mathrm{a} \mathrm{beginner} \mathrm{performs} \mathrm{sur-}$ gery and complications occur, the lack of experience and missing know-how of the surgeon is considered responsible as long as the 
surgeon does not provide evidence to the contrary (reversal of the burden of proof).

RD surgery is a field of ophthalmology, which unlike other subspecialties is not approaching "life style medicine." Successful surgery means vision; no treatment or failure means blindness to the patients. However, the demands and expectations have grown enormously, and increasingly frequent patients sue their surgeon because of discomfort such as metamorphopsia after successful RD surgery, even with full vision.

This sets the frame and environment for teaching complex surgery like VR surgery for RD.

"Experience matters" appears intuitive for surgical performance. Can this hypothesis be proven and how long does it take for a VR surgeon to learn RD surgery? What is the effort to teach a VR surgeon and what does that mean for the allocation of resources for surgical training? Few studies address this question in RD surgery with different methods and varying results. Here we report the success rates and learning curves of 10 VR surgeons beginning with RD surgery with an average count of close to 400 consecutive operations each. Altogether, nearly 4000 operations were analyzed, the largest series being reported in the literature.

\section{Materials and methods}

Retrospectively, the files of all patients undergoing primary rhegmatogenous RD surgery between January 2005 and March 2020 in our hospital were reviewed. The inclusion criteria were eyes with uncomplicated rhegmatogenous RD undergoing buckle surgery or vitrectomy. Excluded were eyes with PVR grade $\mathrm{C}$ or more, eyes with a history of penetrating eye injury, or a history of other vitreoretinal procedures in the past. "Complicated" cases such as eyes with high myopia with macular holes and eyes with retinopathy of prematurity (ROP) and syndromic diseases were also excluded from the analysis.

Failure was defined as diagnosis of redetachment documented in the patient file within 3 months after primary surgery. All patients with surgery between 2007 and 2012 were contacted by mail to detect further redetachments and to get the permission to ask the treating ophthalmologist for the actual status and BCVA. From these 1290 patients, no redetachment was reported, so that we are confident that only few redetachments were missed, who may have had their follow-up in other clinics. Our hospital is the only center for vitreoretinal emergencies in the area serving a population of about 2-3 million people.

Ophthalmology residency programs in Germany take 5 years but do not include intraocular surgery, except intravitreal injections. Training in VR surgery and cataract surgery began in parallel in most cases. General anesthesia is used for all teaching procedures whenever possible. The VR surgical education program initially includes assisting and observing experienced surgeons. Handling under the microscope is then taught with simple extraocular procedures such as conjunctival and scleral sutures or amnion membrane transplantation. Then single steps such as preparing access through the pars plana to the vitreous cavity and cutting vitreous or laser coagulation are performed by the trainee. First complete procedures performed by the trainee under supervision are easy VR cases like removal of liquid silicone or vitreous hemorrhage in pseudophakic eyes. The RD cases included and analyzed in the present study were completely performed by the surgeon in training, and the first procedures were supervised by an experienced surgeon. Thereafter, an experienced surgeon was not present in the OR, but on stand-by for immediate support if required. For these first operations, whenever possible, simple cases were selected (limited detachment, single tear, good view). Allocation of cases to experienced surgeon and trainee had to be done in an individualized and flexible manner, depending on the complexity of the case as well as on the availability and individual experience of each surgeon. Combined cataract and VR operations were performed by the same surgeon in training once sufficient experience with cataract surgery had been acquired typically after approximately 100 phakoemulsifications.

To characterize the background of the trainees at their first RD surgery, data on previous surgical experience was collected from the electronic files and from of the respective surgeons' records.

The study was approved by the local ethic board and adheres to the principles of the declaration of Helsinki.

\section{Results}

Five thousand one hundred one eyes with uncomplicated primary rhegmatogenous RD were operated between January 2005 and March 2020 by 13 surgeons at the university hospital of Regensburg. Ten surgeons started their VR career during this period. These 10 surgeons performed $3786 \mathrm{RD}$ operations (mean 379; median 251; range 71-1053). Overall, primary success rate after one operation was $90 \%$ (3420 of 3786).

In Table 1, the baseline data of the 3786 eyes operated for $\mathrm{RD}$ is listed. Table 2 shows the type of surgery being performed. It should be noted that during the observation period from 2005 to 2020, some changes in techniques and concepts occurred. In the beginning, more buckle surgery was performed, and vitrectomy after 2010 was mainly performed with sutureless $23 \mathrm{G}$ or $25 \mathrm{G}$ systems, whereas before $20 \mathrm{G}$, sutured technique was used. At the end of the period, more combined phakovitrectomies were performed. In 1001 eyes, a combined vitrectomy with cataract surgery was performed. 
Table 1 Baseline data of the 3786 eyes operated for retinal detachment

\begin{tabular}{lll}
\hline $\begin{array}{l}\text { Age (mean) } \\
\text { Gender }\end{array}$ & 61.5 years & \\
Male & 2233 & $59 \%$ \\
Female & 1553 & $41 \%$ \\
Side & & \\
Right eye & 1897 & $50.1 \%$ \\
Left eye & 1889 & $49.9 \%$ \\
Macula status & & \\
Attached & 1969 & $52 \%$ \\
Detached & 1817 & $48 \%$ \\
Lens status & & \\
Phakic & 2521 & $66 \%$ \\
Pseudophakic & 1255 & $33 \%$ \\
Aphakic & 10 & $0,3 \%$ \\
\hline
\end{tabular}

Figure 1 shows the pooled redetachment rate of all 10 surgeons with increasing surgical experience. The respective data is shown in Table 3. Figure 2 shows the individual rates of the 10 surgeons with increasing experience. In Fig. 3, the pooled redetachment rates of 6 male and 4 female surgeons are depicted.

At the time of the first complete RD surgery analyzed in this study, the trainees were $6.2 \pm 1.1$ (range 4-8) years in ophthalmology. They had assisted in $112 \pm 79$ (range 58300) VR procedures, had performed parts of the surgery in $32 \pm 24$ (range 6-35) cases, and had completely performed on their own 19 \pm 9 (range 6-35) easy VR procedures other than RD cases (e.g., vitreous hemorrhage, removal of liquid silicone). The VR surgeons had performed $27 \pm 23$ ( $n=9$, range 4 71) cataract extractions before their first VR operation for RD; one surgeon had started with cataract surgery earlier and had 354 phakoemulsifications.

From the first $250 \mathrm{RD}$ operations (25 of each of the 10 surgeons in training), in 146, a senior surgeon was supervising the complete procedure. The redetachment rate of the 146 supervised procedures was $18 \%$ (27/146), and the redetachment rate of the non-supervised operations was $19 \%$ (20/104).

Table 2 Types of surgery performed to repair retinal detachment

\begin{tabular}{lll}
\hline Vitrectomy gas & 2919 & $77 \%$ \\
Segmental buckle & 418 & $11 \%$ \\
Buckle vitrectomy gas & 174 & $5 \%$ \\
Vitrectomy silicone & 148 & $4 \%$ \\
Encircling buckle & 100 & $3 \%$ \\
Buckle vitrectomy silicone & 27 & $1 \%$ \\
All & 3786 & $100 \%$ \\
\hline
\end{tabular}

Duration of the procedure was $87 \pm 27$ min (mean $+\mathrm{SD}$, $\min 34, \max 191, n=250$ ) for the first $25 \mathrm{RD}$ operations of all 10 surgeons in training. Average time for surgery for 2 surgeons (last 25 procedures each in 2020) having experience with more than $1000 \mathrm{RD}$ procedures was $39 \pm 10(\min 22$, $\max 70, n=50)$ (see also Table 4).

\section{Discussion}

RD surgery is considered to be a benchmark operation for systematic evaluation of ophthalmic surgery [1]. It provides important data for the quality of surgical performance in ophthalmology, which in many other cases is difficult to measure. Here the outcome is "black" (redetachment) or "white" (retina remains attached). Therefore, we have chosen the attached retina as criterion for success. However, retinal reattachment is not the only factor relevant for the patient in RD surgery. Visual acuity depends on many variables, and since limited postoperative visual acuity is not necessarily due to an unsuccessful surgery, visual acuity was not included in the analysis. Other surgeon-associated factors however, like retinal folds, may be massively disturbing despite reattached retina and good visual acuity. Perfluorcarbon leftovers (subretinal or preretinal) may also cause major symptoms, but were also not analyzed in the present study.

Our results show that beginning surgeons have a primary success rate of about $80 \%$ for their first RD operations, which is quite an acceptable rate, showing that it is reasonable to have beginners perform RD surgery. The variability of the individual learning curve is relatively high, as shown in Fig. 2. Many factors, especially case selection, intensity of previous training experience, and individual surgeon factors, may explain these differences. After about 200 operations, the redetachment rate stabilizes just below $10 \%$.

In the literature, varying results have been published from studies using different methods. Our approach, to observe the success rates of a relatively large number of VR surgeons from their beginning, has not been reported so far. Older and smaller series suggested that surgical experience has an effect on RD surgery outcome [2]. Primary vitrectomy for RD has been described to require 120-180 cases or 2-3-year experience until redetachment rates remain stable. On the other hand, even for the first cases in beginners, acceptable success rates were reported [3]. Keller concluded that the first 100 RD operations were crucial when monitoring the learning curve of surgical performance [4]. Sagong suggested that only 30 cases were necessary to reach stable success rates in buckle surgery [5].

On the other hand, Ehrlich et al. more recently found no difference in success rates with small gauge vitrectomy between fellows and consultants [6]. Mazinani et al. also described that primary anatomical success rates did not correlate 
Fig. 1 Pooled redetachment rates of 10 VR surgeons in training with increasing experience. The corresponding data are shown in Table 1

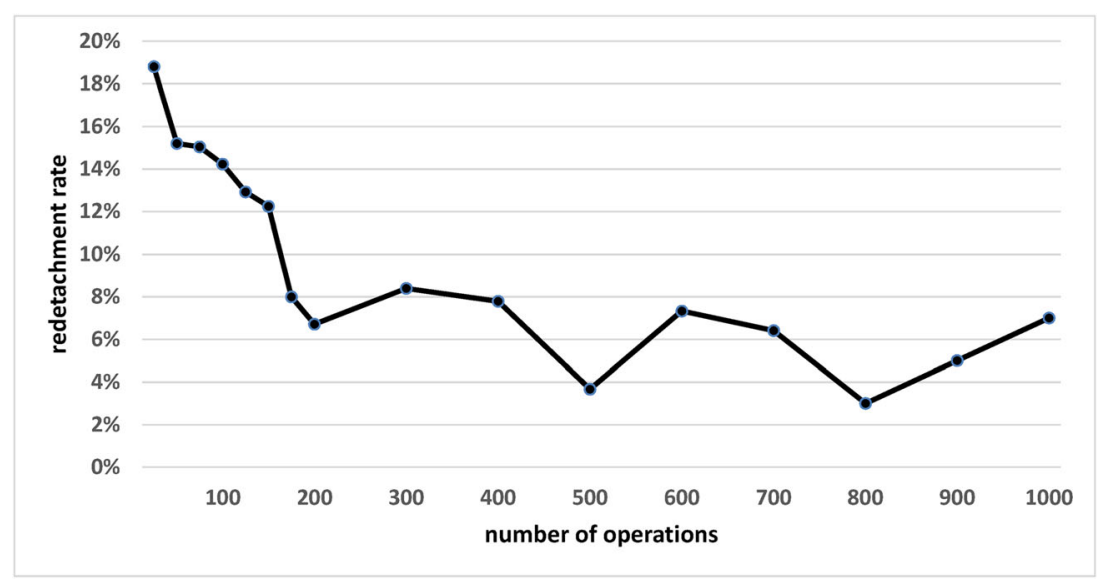

with the number of vitreoretinal procedures performed by each surgeon [7]. However, a certain improvement of success rates was found in some surgeons, when the first and the second half of the observation period was compared [7]. An accompanying editorial [8] addresses some fundamental questions of learning and teaching surgery. Volume alone does not account for skill levels [9]. The concept of "deliberate practice," discussing and watching cases of others, especially surgical failures, sharing experience, and discussion amongst colleagues of similar level of experience and with their mentors, can largely improve performance, leading finally to a level of "excellence." Teaching on the other hand is a good opportunity for senior surgeons to further improve performance, as young fellows challenge fixed dogmas and thus may prevent their mentors from becoming rigid in their long-standing habits.

Interestingly, Heimann [10] described that younger, less experienced surgeons may have even better results than more experienced ones. He discussed case selection as a possible reason but also mentioned that younger surgeons might be more open to adapt to technical and conceptual advancements, whereas older surgeons may fall behind. The surgeon factor is a delicate item, burdened with personal vanities and difficult to discuss in the scientific literature [11].

There has been a great deal of discussion with respect to a recent study showing that patients operated by female surgeons had a lower mortality rate [12]. It was speculated that the gender barriers women experience during their surgical training and daily routine might lead to a selection of a cohort of female surgeons that are proportionally more skilled, motivated, and harder working. In our series, too, it appeared that female surgeons might have a faster learning curve than male surgeons. However, other factors like case selection, publication bias, or coincidence must be considered possible explanations, which prevents definite conclusions.

Overall, the primary success rate of $90 \%$ was relatively high in our study, considering the skill levels of beginning surgeons. This may be explained by the exclusion of complicated cases. The UK database found an $87 \%$ success rate [13] and a recent Canadians study $85 \%$ [14], and the ERVS found $85 \%$ [15]. With specialized VR surgeons, the standard for primary success was set in the region of 85-90\% [16]. Furthermore, success rates are highly dependent on case selection. Trainees should whenever possible start with simple cases. Success rates in more difficult cases are likely to improve much later. Even when success rates as demonstrated here reach a stable level, success rates in complicated, unusual cases may improve later on, no longer easily detectable by simple statistical approaches.

The German healthcare system - like many others - has no formal fellowships for subspecialization in ophthalmology. Therefore, no specific education program exists. Surgical training usually starts after the residency. Most ophthalmic surgeons in smaller departments have to cover both, anterior and posterior intraocular surgery. Although teaching hospitals, which are mainly under public sponsorship, try to train

Table 3 Data for Fig. 1 showing pooled redetachment rates of 10 VR surgeons in training with increasing surgical experience

\begin{tabular}{|c|c|c|c|c|c|c|c|c|c|c|c|c|c|c|c|c|}
\hline $\begin{array}{l}\text { Surgical experience } \\
\text { Number of operations }\end{array}$ & 25 & 50 & 75 & 100 & 125 & 150 & 175 & 200 & 300 & 400 & 500 & 600 & 700 & 800 & 900 & 1000 \\
\hline Number of surgeons & 10 & 10 & 10 & 9 & 9 & 8 & 6 & 6 & 5 & 5 & 3 & 3 & 3 & 1 & 1 & 1 \\
\hline $\begin{array}{l}\text { Number of operations performed by the surgeons with } \\
\text { respective surgical experience }\end{array}$ & 250 & 250 & 246 & 225 & 209 & 188 & 150 & 149 & 500 & 391 & 300 & 300 & 281 & 100 & 100 & 100 \\
\hline$\%$ Redetachment & 18.8 & 15.2 & 15.0 & 14.2 & 12.9 & 12.2 & 8.0 & 6.7 & 8.0 & 8.0 & 3.7 & 7.3 & 6.4 & 3.0 & 5.0 & 7.0 \\
\hline
\end{tabular}


Fig. 2 Individual redetachment rates of $10 \mathrm{VR}$ surgeons in training with increasing experience

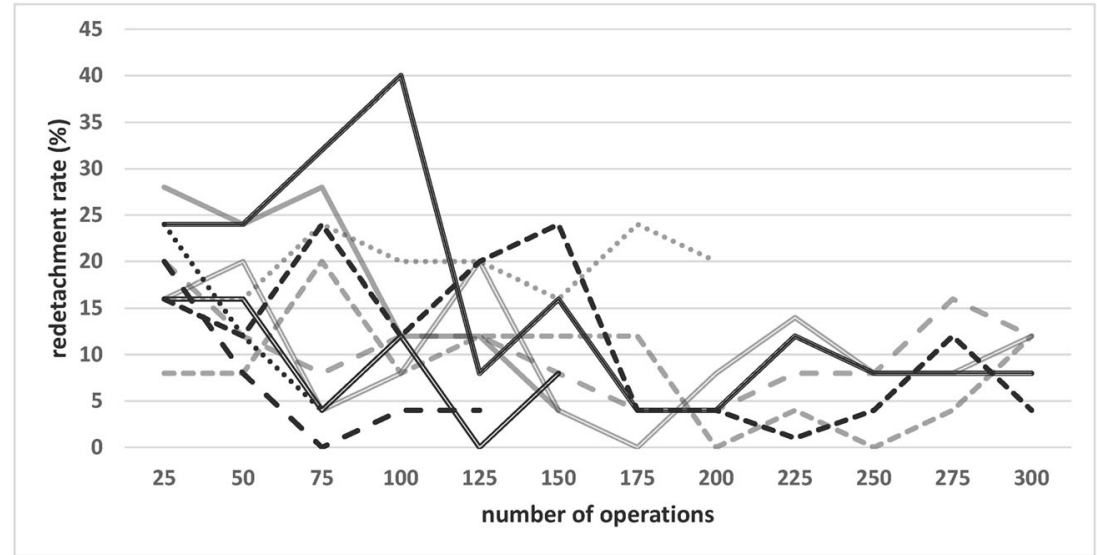

surgeons in an organized and responsible manner, the specific circumstances require a lot of improvisation and flexibility, especially for unplannable operations such as RD surgery. Experienced surgeons, willing to teach, are the cornerstone for a successful program. Their availability is limited. The term of notice for civil servant physicians is 1 day. In addition, it is mostly not allowed in Germany for pregnant female physicians to perform surgery, and all female surgeons in this study had at least a 1-year baby break. Especially in smaller ophthalmology departments, these uncertainties of planning may be difficult to harmonize and bring in line with patient care, economic constraints, and teaching.

Teaching surgery requires time and resources. We have shown here that trainees need more than twice as long time for a RD operation than experienced surgeons do. Moreover, for the first operations, an experienced surgeon has to be present to safely guide the beginner through the various steps. The effort for educating surgeons is high, and it is mandatory that a healthcare system provides the necessary financial and personnel resources.

Limitations of our study are its retrospective design, a possible selection bias of easier cases for VR surgeons in training and the incomplete follow-up of some surgeons (4 out of 10) that did not accomplish at least 200 RD operations. Prospective studies in general had a tendency to show less positive results compared to retrospective analysis [17, 18]. On the other hand, the $23 / 25 \mathrm{G}$ arm of the prospective VIPER study also showed a $90 \%$ primary success rate [17]. Due to the retrospective design and not complete follow-up of all cases, we acknowledge that we may have missed some failures. Moreover, if the retinal was flat under liquid silicone tamponade after 3 months, it was considered non-redetached, although some redetachments may occur later after removal of the liquid silicone. Other studies used a 6-month period postoperatively before assessing the success of surgery, but the vast majority of redetachments typically occur in the first 3 months [17]. This however should have the same effect on all subgroups. Despite these limitations, our series with nearly 4000 operations performed by 10 VR surgeons provides a profound basis for evaluating the learning curve in RD surgery.

In conclusion, our study shows that VR surgeons in training had a primary success rate of approximately $80 \%$ when starting RD operations. The redetachment rate steadily
Fig. 3 Pooled redetachment rates of RD surgery in 4 female and 6 male VR surgeons in training with increasing experience of the surgeons

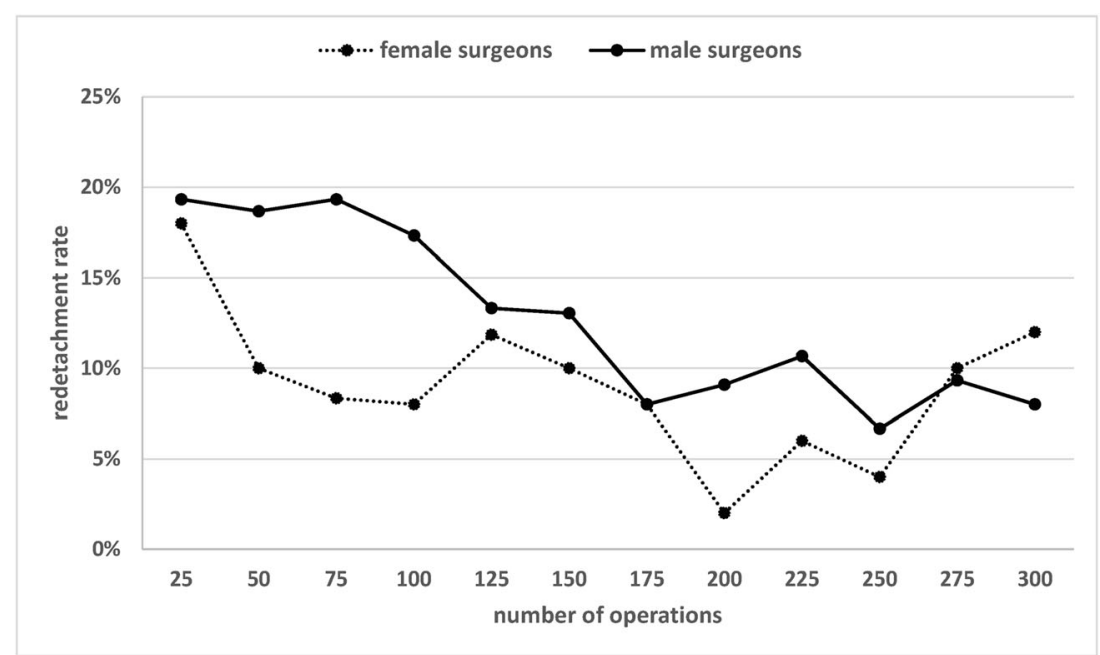


Table 4 Cutting-suture time of the first $25 \mathrm{RD}$ operations of all 10 trainee surgeons (1-10) and the time of the procedure of two surgeons with large experience of more than $1000 \mathrm{VR}$ operations for $\mathrm{RD}(\mathrm{A}, \mathrm{B})$

\begin{tabular}{|c|c|c|c|c|c|c|c|c|c|c|c|c|}
\hline Surgeon & 1 & 2 & 3 & 4 & 5 & 6 & 7 & 8 & 9 & 10 & A & $\mathrm{B}$ \\
\hline Time of procedure, mean of 25 procedures (min) & 70 & 98 & 93 & 75 & 86 & 75 & 95 & 108 & 87 & 82 & 38 & 40 \\
\hline $\mathrm{SD}(\mathrm{min})$ & 7 & 23 & 26 & 18 & 15 & 15 & 34 & 32 & 31 & 25 & 9 & 12 \\
\hline Minimum time (min) & 34 & 67 & 55 & 58 & 63 & 47 & 55 & 62 & 51 & 54 & 22 & 22 \\
\hline Maximum time (min) & 107 & 170 & 172 & 124 & 113 & 103 & 159 & 191 & 170 & 160 & 62 & 70 \\
\hline
\end{tabular}

decreased and stabilized just under $10 \%$ after about 200 operations. The individual learning curves varied widely. In our cohort, female surgeons in training had a faster learning curve. The training of VR surgeons requires considerable resources.

Funding Open Access funding enabled and organized by Projekt DEAL.

\section{Declarations}

Ethics approval All procedures performed in studies involving human participants were in accordance with the ethical standards of the (place name of institution and/or national research committee) and with the 1964 Helsinki declaration and its later amendments or comparable ethical standards.

Informed consent Informed consent was waived because of the retrospective design of the study.

Conflict of interest The authors declare no competing interests.

Open Access This article is licensed under a Creative Commons Attribution 4.0 International License, which permits use, sharing, adaptation, distribution and reproduction in any medium or format, as long as you give appropriate credit to the original author(s) and the source, provide a link to the Creative Commons licence, and indicate if changes were made. The images or other third party material in this article are included in the article's Creative Commons licence, unless indicated otherwise in a credit line to the material. If material is not included in the article's Creative Commons licence and your intended use is not permitted by statutory regulation or exceeds the permitted use, you will need to obtain permission directly from the copyright holder. To view a copy of this licence, visit http://creativecommons.org/licenses/by/4.0/.

\section{References}

1. Aylward B (2011) Revalidation and retinal detachment. Ophthalmologica 226(Suppl 1):58-59. https://doi.org/10.1159/ 000328214

2. Miki D, Hida T, Hotta K et al (2001) Comparison of scleral buckling and vitrectomy for retinal detachment resulting from flap tears in superior quadrants. Jpn J Ophthalmol 45:187-191. https://doi. org/10.1016/s0021-5155(00)00377-4

3. Dugas B, Lafontaine P-O, Guillaubey A et al (2009) The learning curve for primary vitrectomy without scleral buckling for pseudophakic retinal detachment. Graefes Arch Clin Exp Ophthalmol 247:319-324. https://doi.org/10.1007/s00417-0080997-y
4. Keller J, Haynes RJ, Sparrow JM (2016) Sequential hypothesis testing to characterise the learning curve and monitor surgical performance in retinal detachment surgery. Ophthalmologica 235: 157-162. https://doi.org/10.1159/000443749

5. Sagong M, Chang W (2010) Learning curve of the scleral buckling operation: lessons from the first 97 cases. Ophthalmologica 224: 22-29. https://doi.org/10.1159/000233232

6. Ehrlich R, Ahmad N, Welch S et al (2011) Vitreoretinal fellow surgical outcome of small gauge pars plana vitrectomy for acute rhegmatogenous retinal detachment. Graefes Arch Clin Exp Ophthalmol 249:1147-1152. https://doi.org/10.1007/s00417-0111638-4

7. Mazinani BAE, Rajendram A, Walter P et al (2012) Does surgical experience have an effect on the success of retinal detachment surgery? Retina (Philadelphia, Pa ) 32:32-37. https://doi.org/10.1097/ IAE.0B013E3182411CD2

8. Schimel AM, Grand MG, Flynn HW (2012) Surgery for retinal detachment: does experience matter? Retina (Philadelphia, $\mathrm{Pa}$ ) 32:1-3. https://doi.org/10.1097/IAE.0B013E3182411D04

9. Ericsson KA, Nandagopal K, Roring RW (2009) Toward a science of exceptional achievement: attaining superior performance through deliberate practice. Ann N Y Acad Sci 1172:199-217. https://doi.org/10.1196/annals.1393.001

10. Heimann H, Zou X, Jandeck C et al (2006) Primary vitrectomy for rhegmatogenous retinal detachment: an analysis of 512 cases. Graefes Arch Clin Exp Ophthalmol 244:69-78. https://doi.org/10. 1007/s00417-005-0026-3

11. Heimann H, Bornfeld N, Bartz-Schmidt UK et al (2009) Einfluss des Operateurs auf die Operationsergebnisse bei rhegmatogener Ablatio retinae im Rahmen der "Scleral Buckling versus Primary Vitrectomy in Rhegmatogenous Retinal Detachment Study" (Analysis of the surgeon factor in the treatment results of rhegmatogenous retinal detachment in the "scleral buckling versus primary vitrectomy in rhegmatogenous retinal detachment study"). Klin Monbl Augenheilkd 226:991-998. https://doi.org/10.1055/s0028-1109873

12. Wallis CJ, Ravi B, Coburn N et al (2017) Comparison of postoperative outcomes among patients treated by male and female surgeons: a population based matched cohort study. BMJ 359:j4366. https://doi.org/10.1136/bmj.j4366

13. Jackson TL, Donachie PHJ, Sallam A et al (2014) United Kingdom National Ophthalmology Database study of vitreoretinal surgery: report 3, retinal detachment. Ophthalmology 121:643-648. https:// doi.org/10.1016/j.ophtha.2013.07.015

14. Dotan A, Johnson D, Kherani A et al (2019) Success Rates for retinal detachment repair in Alberta: a physician learning program initiative. Ophthalmologica 241:170-172. https://doi.org/10.1159/ 000492538

15. Adelman RA, Parnes AJ, Michalewska $Z$ et al (2014) Clinical variables associated with failure of retinal detachment repair: the European vitreo-retinal society retinal detachment study report number 4. Ophthalmology 121:1715-1719. https://doi.org/10. 1016/j.ophtha.2014.03.012 
16. Comer MB, Newman DK, George ND et al (2000) Who should manage primary retinal detachments? Eye (Lond) 14(Pt 4):572578. https://doi.org/10.1038/eye.2000.145

17. Walter P, Hellmich M, Baumgarten S et al (2017) Vitrectomy with and without encircling band for pseudophakic retinal detachment: VIPER Study Report No 2-main results. Br J Ophthalmol 101:712718. https://doi.org/10.1136/bjophthalmol-2016-309240

18. Heimann H, Bartz-Schmidt KU, Bornfeld N et al (2007) Scleral buckling versus primary vitrectomy in rhegmatogenous retinal detachment: a prospective randomized multicenter clinical study. Ophthalmology 114:2142-2154. https://doi.org/10.1016/j.ophtha. 2007.09.013

Publisher's note Springer Nature remains neutral with regard to jurisdictional claims in published maps and institutional affiliations. 